\title{
The promises and perils of nurse-led flexible sigmoidoscopy screening
}

\author{
Paul Moayyedi BSc MB ChB PhD MPH FRCP(London) FRCPC
}

$\mathrm{P}$ ublic awareness of the need for colorectal cancer (CRC) screening is growing thanks to media personalities such as Katie Couric (1), and other publicity drives. Many Canadian provinces have responded to this by developing CRC screening programs. The model most provinces have considered is the fecal occult blood test (FOBT), in line with recommendations by Health Canada (2). These initiatives are welcomed, although FOBTs only reduce CRC mortality by $15 \%$ to $25 \%$, and screening programs that prevent $\mathrm{CRC}$, as well as detect the disease early, may be of greater benefit. The current alternative screening modalities are flexible sigmoidoscopy (FS) and colonoscopy (3). FS detects adenomatous polyps and malignancy up to the splenic flexure, where two-thirds of all CRCs are located. Therefore, the removal of adenomatous polyps should reduce the incidence of CRC. FS is currently being evaluated in three randomized controlled trials (RCTs) (4-6) assessing almost 360,000 patients. The stage that CRC is detected is earlier than seen with symptomatic cancers (4-6). The impact of FS on CRC incidence and mortality during follow-up will be reported in the near future. The advantage of FS is that the bowel preparation required is less rigorous, and the procedure is easier and quicker to perform than a colonoscopy, with no sedation required. On the other hand, FS will potentially miss right-sided lesions but colonoscopy views the whole colon; thus, colonoscopy is probably the most effective strategy. However, the cost of offering colonoscopy as a screening program is prohibitive in the Canadian health care setting. FS would also be difficult to deliver in Canada because there are insufficient clinicians to provide the service (7) and their time would be expensive. FS is relatively straightforward to perform, and if a less expensive section of the health care workforce could deliver this service then FS could be a viable screening option.

The concept of training nurses to perform FS dates back over 30 years (8). Nurse endoscopy has subsequently been well described, particularly in centres in the United States (US) $(9,10)$ and the United Kingdom (UK) $(11,12)$. Studies have demonstrated that adequately trained nurses perform FS at least as competently as gastroenterologists. An RCT (13) of 328 patients undergoing FS screening reported that the missed polyp rates determined by a repeat procedure (by a gastroenterologist) were similar in both groups. Data suggest that patient satisfaction is comparable among general surgeons, gastroenterologists and nurses performing screening FS (14).
Discomfort during the procedure is perceived by the patient to be similar between clinician and nurse FS (15). Serious adverse events are fortunately rare with FS and no study has reported any major complications (9-15), including one study series of 1000 patients referred to a nurse-led service (16).

All evidence points to nurses performing FS screening just as well as clinicians. An MD degree does not confer any particular technical skill, and it seems reasonable that adequate training is a far more important indicator of the ability to perform FS. Nurses are less expensive than doctors, and cost-containment is a major concern for the publicly funded Canadian health care system. If this is the case, why has nurse-led FS taken so long to develop in Canada? Dobrow et al (17) provided some of the answers in this issue of The Canadian Journal of Gastroenterology (pages 301-308).

An important problem in developing nurse-led screening FS is providing adequate training. The FS program described in the study by Dobrow et al (17) was adapted from UK and US experiences, with a theoretical component consisting of didactic teaching and a practical component consisting of 'hands-on' experience. The number of procedures a nurse needs to perform to become competent is uncertain. One study suggested the mean number of supervised FS needed to obtain competency was 20, with nurses and doctors learning at similar rates (18). A survey of American institutions (19) found that the number of supervised procedures needed before a nurse was granted competency was set at a much more conservative level (range 50 to 300 procedures). In the UK, nurse endoscopy is particularly well developed and a survey of all hospitals in the UK revealed that almost $50 \%$ of responding hospitals employed a nurse endoscopist (20). Training is also formalized, and largely occurs within a national framework in centres approved by The Joint Advisory Group on Gastrointestinal Endoscopy (21). Nurses need to perform 50 supervised FS with a further 50 procedures where immediate advice is available. A key feature of the UK program is that the trainer needs to be competent and appropriately trained to teach through a 'train-the-trainer' course, and the training centre needs to provide a suitable environment for learning. These requirements are also well defined with objective measures (21). There are also some indicators of how to assess competency with nurses needing to intubate the descending colon in $90 \%$ of cases and taking diagnostic biopsies (21). The program described by Dobrow et al (17)

Division of Gastroenterology, Department of Medicine, McMaster University Medical Centre, Hamilton, Ontario

Correspondence: Dr Paul Moayyedi, Department of Medicine, McMaster University Medical Centre, 1200 Main Street West,

Health Sciences Centre - 4W8B, Hamilton, Ontario L8N 325. Telephone 905-521-2100 ext 76764, fax 905-521-4958,

e-mail moayyep@mcmaster.ca

Received and accepted for publication March 28, 2007 
largely follows this approach, with trainees needing to perform 64 procedures to obtain competency. The problem is that the optimum number of procedures most nurses need to obtain competency has not been well evaluated; the figures have been determined by expert opinion. There is also the problem of how to assess competency. There are a number of objective criteria that have been elucidated for colonoscopy (22), but this is not the case for FS. Polyp detection rates and withdrawal times are probably also important in FS but these parameters need to be formally evaluated and quantified.

Medicolegal issues have also been raised as a concern in developing nurse endoscopy. This is not just an issue for nurse endoscopy but relates to all areas of advanced practice nursing. Nurses have their own insurance that should cover malpractice suits for issues relating to FS. However, FS is a delegated act and is only performed under the supervision of a clinician. If a nurse has a major complication while performing FS, such as missing a cancer, then the supervising clinician could be sued. Dobrow et al (17) obtained special liability protection from the Canadian Medical Protection Association, but this would have to be routinely available if nurse endoscopy is to be viable as a national or provincial program. This should be possible because nurse endoscopy occurs in the US, which is a more litigious society. Furthermore, there is a large body of evidence that suggests that nurses miss cancer or cause complications at a comparable rate to physicians; thus, any litigation based on the qualification of the person performing the procedure is unlikely to be successful provided the individual is adequately trained.

A cynic might argue that reimbursement issues are the most significant barrier to nurse endoscopy. Most gastroenterologists and general surgeons in Canada are paid on a fee-for-service system and endoscopy is a key source of income. Nonmedical salaried personnel performing these procedures will take away income from clinicians and, thus, it is not surprising that gastroenterologists and surgeons have not clamoured to develop nurse endoscopy. This point of view has a grain of truth but endoscopy waiting lists are a major problem in most hospitals; thus, clinicians have more than enough work and any extra help would be welcome particularly as CRC screening increases. Considerable time will be invested in teaching a nurse FS, which could impact on a clinician's earnings, but this is conceptually no different from training a gastroenterologist or a surgical resident. The nurse will still need nominal supervision once trained and this also impacts on a clinician's time. There will need to be national and provincial negotiations to ensure the attending clinician is appropriately remunerated. This could be a barrier to nurse endoscopy flourishing in Canada but is not insurmountable.

Another concern is that there is not only a shortage of gastroenterologists in Canada (7) but also nurses. Therefore, there may be an insufficient number of nurses to develop nurse endoscopy. However, these workforce issues are also present in the UK where nurse endoscopy is common and expanding. Nurses often thrive on extending their role and welcome new opportunities to develop new skills. Offering a nurse endoscopy program could result in a more stimulating and fulfilling job, which would help retain nursing staff. It is reassuring that this seems to be the experience of this pilot project. The other issue is what type of nurse should be recruited as a nurse endoscopist. The obvious pool to recruit from is those currently working in the endoscopy unit. This is problematic because most nurse endoscopists will perform FS on a part-time basis only and will likely have other roles as well. If nurse endoscopy is to act as support for clinicians then it could potentially lead to job dissatisfaction because the nurse will become used to playing a more active role in the procedure. Nurse endoscopists could, therefore, be recruited from other areas and those that are recruited from the endoscopy unit could be given other extended or supervisory roles when they are not endoscoping.

The main message from Dobrow et al (17) is that referrals for nurse-led FS screening are not overwhelming. This does not appear to be due to reluctance on the part of patients to have a nurse perform their procedure (17), which is confirmed by a large RCT (23) performed in the UK in which nearly all patients were happy to have a nurse perform their endoscopic procedure. Dobrow et al (17) gave alternative suggestions as to why referral rates were so low. Perhaps the most likely explanation is that FS is not seen by patients or primary care physicians as an optimal CRC screening strategy. It is not as cheap as FOBT and is not as potentially effective as colonoscopy screening. Therefore, government programs will focus on FOBT and some patients and their physicians will demand colonoscopy screening while FS, being neither the best nor the cheapest approach, may become the least popular alternative. This attitude may change when RCT data on the efficacy of screening FS are released but, even if this is not the case, it does not preclude the development of nurse endoscopy in Canada. Nurses could also perform FS on symptomatic patients where this procedure is indicated, such as the young person with rectal bleeding. Nurses could also perform upper gastrointestinal endoscopy, which is the most common endoscopic procedure performed by nurses in the UK $(20,23)$. There is a large body of research to state that this approach is sensible, although there is still room for more data. The MultiInstitution Nurse Endoscopy Trial (MINuET) (24) in the UK involved 1888 patients randomly assigned to an endoscopy (either upper gastrointestinal endoscopy or FS) performed by a nurse or a doctor. Initial satisfaction was statistically significantly higher for nurse endoscopy but, during one year, there was a trend for quality of life to be higher in those allocated to have an endoscopy performed by a doctor. This resulted in an $87 \%$ probability that clinician endoscopy was the more cost-effective strategy (24). This result is difficult to understand because the diagnostic accuracy was the same for both groups, and this may just be a chance finding because the trend did not achieve statistical significance. This issue needs to be evaluated by another study in a different setting, and perhaps more research can be conducted in Canada as nurse endoscopy develops.

Dobrow et al (17) have shown that a nurse-led FS program is feasible in Canada, although there are hurdles to climb. Through the dedication and vision of these researchers, this program is currently being piloted in a wider Ontario setting involving community hospitals as well as other teaching hospitals. If this extended pilot is successful, everyone stands to gain. Patients will experience shorter waiting lists, third-party payers will have a more efficient service, nurses can have an extended role that gives them greater job satisfaction and gastroenterologists can have the time to focus on more technically demanding procedures such as colonoscopy, which will be in ever increasing demand as CRC screening takes off in Canada. 


\section{REFERENCES}

1. Cram P, Fendrick AM, Inadomi J, Cowen ME, Carpenter D, Vijan S. The impact of a celebrity promotional campaign on the use of colon cancer screening: The Katie Couric effect. Arch Intern Med 2003;163:1601-5.

2. McLeod RS; Canadian Task Force on Preventive Health Care. Screening strategies for colorectal cancer: A systematic review of the evidence. Can J Gastroenterol 2001;15:647-60.

3. Leddin D, Hunt R, Champion M, et al; Canadian Association of Gastroenterology; Canadian Digestive Health Foundation. Canadian Association of Gastroenterology and the Canadian Digestive Health Foundation: Guidelines on colon cancer screening. Can J Gastroenterol 2004;18:93-9.

4. UK Flexible Sigmoidoscopy Screening Trial Investigators. Single flexible sigmoidoscopy screening to prevent colorectal cancer: Baseline findings of a UK multicentre randomised trial. Lancet 2002;359:1291-300.

5. Segnan N, Senore C, Andreoni B, et al; SCORE Working Group Italy. Baseline findings of the Italian multicenter randomized controlled trial of "once-only sigmoidoscopy" - SCORE. J Natl Cancer Inst 2002;94:1763-72.

6. Weissfeld JL, Schoen RE, Pinsky PF, et al; PLCO Project Team. Flexible sigmoidoscopy in the PLCO cancer screening trial: Results from the baseline screening examination of a randomized trial. J Natl Cancer Inst 2005;97:989-97.

7. Moayyedi P, Tepper J, Hilsden R, Rabeneck L. International comparisons of manpower in gastroenterology. Am J Gastroenterol 2007;102:478-81.

8. Spencer RJ, Ready RL. Utilization of nurse endoscopists for sigmoidoscopic examinations. Dis Colon Rectum 1977;20:94-6.

9. Schoenfeld P, Piorkowski M, Allaire J, Ernst R. Holmes L. Flexible sigmoidoscopy by nurses: State of the art 1999 Gastroenterol Nurs 1999;22:254-61.

10. Schroy PC, Wiggins T, Winawer SJ, Diaz B, Lightdale CJ. Video endoscopy by nurse practitioners: A model for colorectal cancer screening. Gastrointest Endosc 1988;34:390-4.

11. Duthie GS, Drew PJ, Hughes MA, et al. A UK training programme for nurse practitioner flexible sigmoidoscopy and a prospective evaluation of the practice of the first UK trained nurse flexible sigmoidoscopist. Gut 1998;43:711-4.

12. Basnyat PS, Gomez KF, West J, Davies PS, Foster ME. Nurse-led direct access endoscopy clinics: The future? Surg Endosc 2002;16:166-9
13. Schoenfeld P, Lipscomb S, Crook J, et al. Accuracy of polyp detection by gastroenterologists and nurse endoscopists during flexible sigmoidoscopy: A randomized trial. Gastroenterology 1999;117:312-8.

14. Schoenfeld PS, Cash B, Kita J, Piorkowski M, Cruess D, Ransohoff D. Effectiveness and patient satisfaction with screening flexible sigmoidoscopy performed by registered nurses. Gastrointest Endosc 1999;49:158-62.

15. Maule WF. Screening for colorectal cancer by nurse endoscopists. N Engl J Med 1994;330:183-7.

16. Maruthachalam K, Stoker E, Nicholson G, Horgan AF. Nurse led flexible sigmoidoscopy in primary care - the first thousand patients. Colorectal Dis 2006;8:557-62.

17. Dobrow MJ, Cooper MA, Gayman K, Pennington J, Matthews J, Rabeneck L. Referring patients to nurses: Outcomes and evaluation of a nurse flexible sigmoidoscopy training program for colorectal cancer screening. Can J Gastroenterol 2007;21:301-8

18. DiSario JA, Sanowski RA. Sigmoidoscopy training for nurses and resident physicians. Gastrointest Endosc 1993;39:29-32.

19. Cash BD, Schoenfeld PS, Ransohoff DF. Licensure, use, and training of paramedical personnel to perform screening flexible sigmoidoscopy. Gastrointest Endosc 1999;49:163-9.

20. Pathmakanthan S, Murray I, Smith K, Heeley R, Donnelly M. Nurse endoscopists in United Kingdom health care: A survey of prevalence, skills and attitudes. J Adv Nurs 2001;36:705-10.

21. The Joint Advisory Group on Gastrointestinal Endoscopy. Guidelines for the training, appraisal and assessment of trainees in GI endoscopy. <http://www.thejag.org.uk/guidelines.htm> (Version current at March 29, 2007).

22. Rex DK, Petrini JL, Baron TH, et al; ASGE/ACG Taskforce on Quality in Endoscopy. Quality indicators for colonoscopy. Am J Gastroenterol 2006;101:873-85.

23. Smale S, Bjarnason I, Forgacs I, et al. Upper gastrointestinal endoscopy performed by nurses: Scope for the future? Gut 2003;52:1090-4.

24. Williams J, Russell I, Durai D, et al. What are the clinical outcome and cost-effectiveness of endoscopy undertaken by nurses when compared with doctors? A Multi-Institution Nurse Endoscopy Trial (MINuET). Health Technol Assess 2006;10:1-195. 


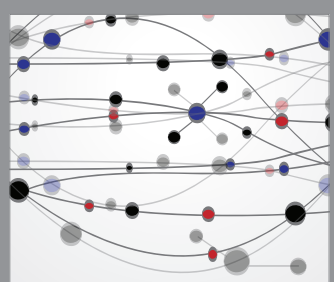

The Scientific World Journal
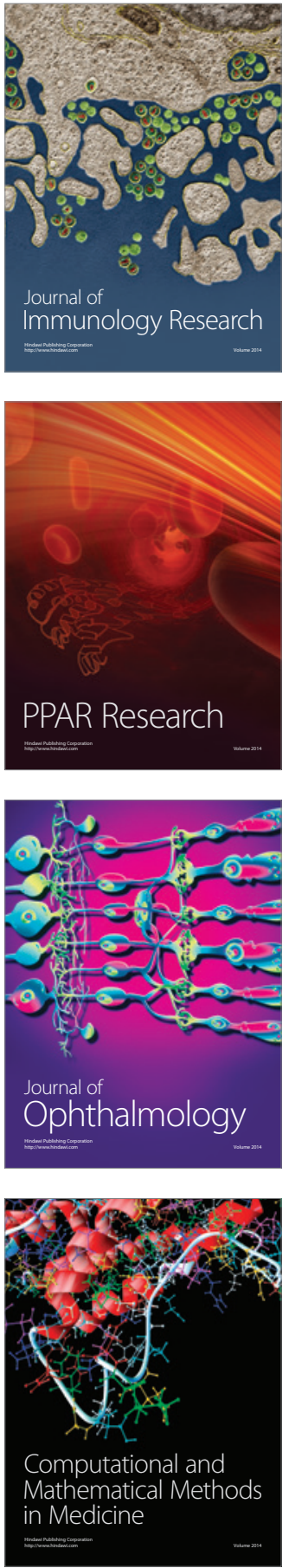

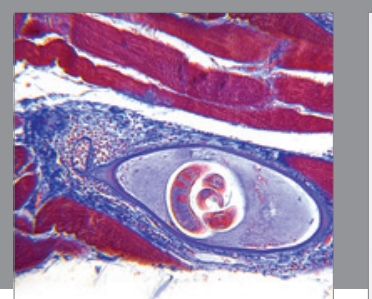

Gastroenterology Research and Practice

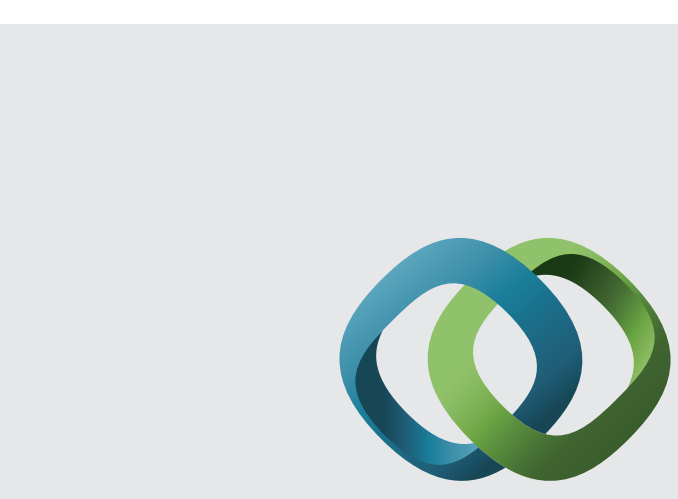

\section{Hindawi}

Submit your manuscripts at

http://www.hindawi.com
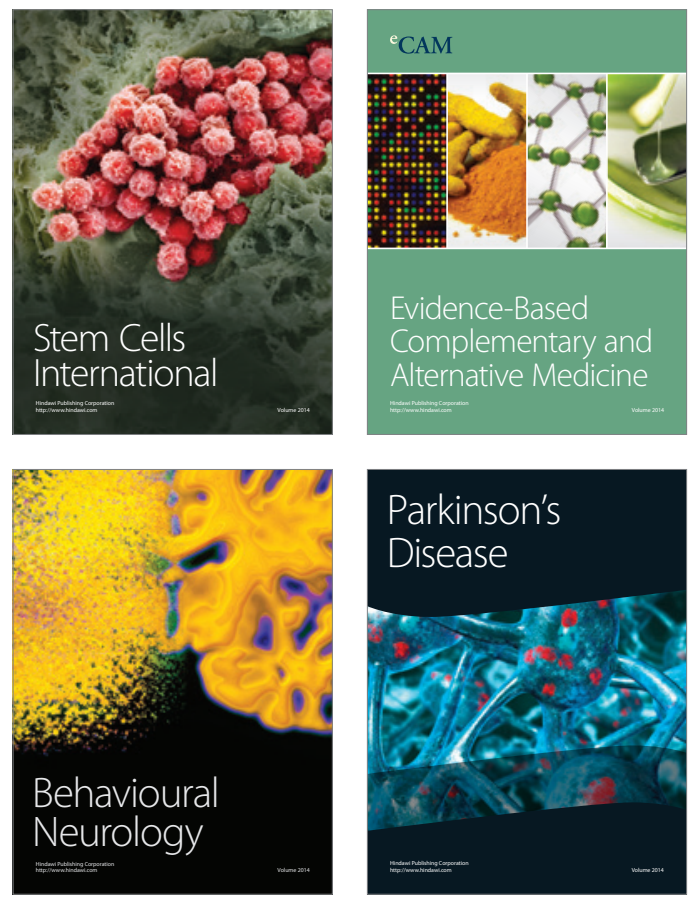
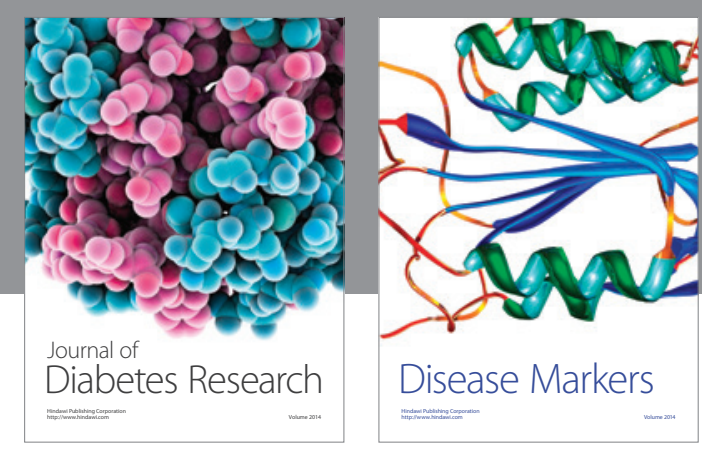

Disease Markers
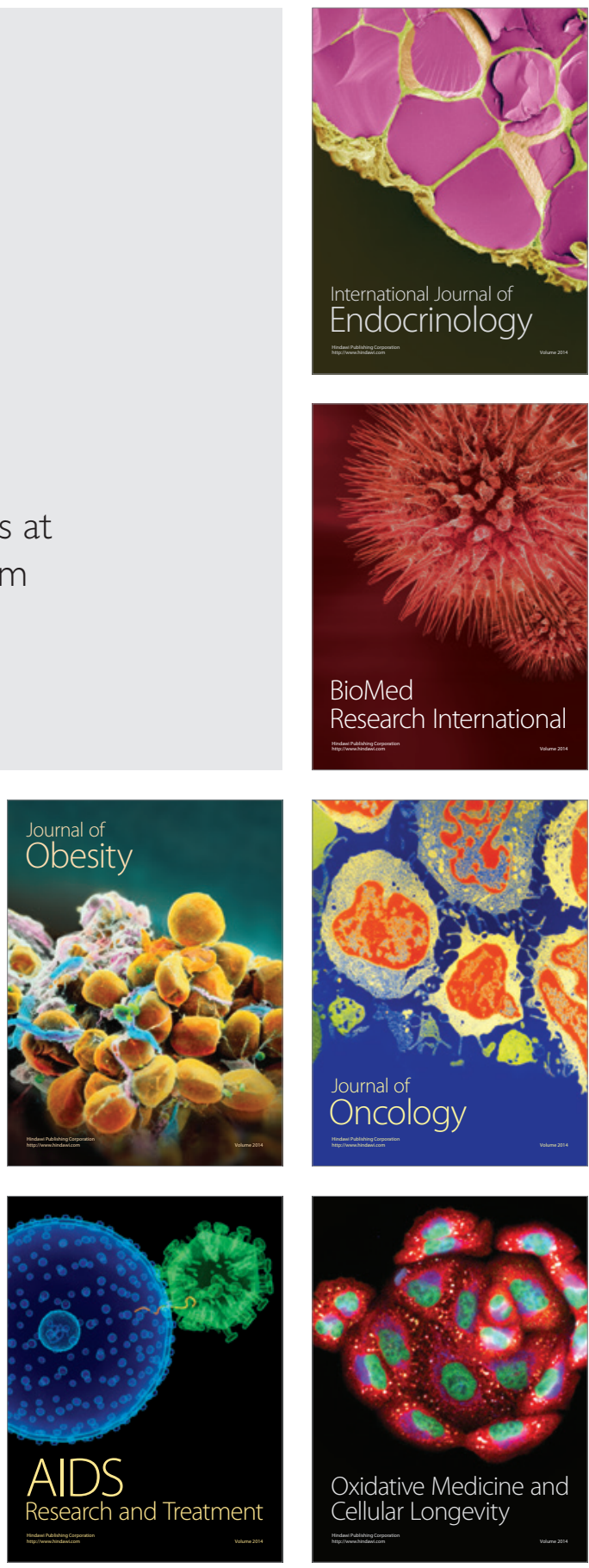